\title{
Autonomic neuropathy in systemic sclerosis: a case report and evaluation of six patients
}

\author{
C SONNEX,* E PAICE, AND A G WHITE
}

From the Department of Rheumatology, Whittington Hospital, Highgate Hill, London.

SUMMARY We describe a case of systemic sclerosis with sympathetic and parasympathetic neuropathy and detail autonomic testing in six further patients. Of these six patients, three showed early parasympathetic damage. None of the patients had evidence of peripheral neuropathy, and there was no correlation between the presence of autonomic dysfunction and the severity of Raynaud's phenomenon.

Autonomic neuropathy has not previously been reported in systemic sclerosis to our knowledge. Autonomic neuropathy has been described in rheumatoid arthritis ${ }^{12}$ and systemic lupus erythematosus, ${ }^{3}$ and impotence was recently described in systemic sclerosis ${ }^{4}$ but without formal studies of autonomic function. Other neurological manifestations of systemic sclerosis have been described but are rare. A mild peripheral neuropathy has been reported. ${ }^{56}$ as has trigeminal neuralgia. ${ }^{7-9}$ Subacute combined degeneration of the cord following vitamin $B_{12}$ deficiency secondary to sclerodermatous involvement of the small intestine has also been recorded. ${ }^{10}$

We describe a patient with systemic sclerosis and autonomic neuropathy and detail our investigation of the autonomic nervous system in six other patients with scleroderma and eight control patients.

\section{Case report}

A 50 year old Asian woman first presented in 1968 with dysphagia, depigmentation and tightness of the skin of the hands, and Raynaud's phenomenon. Systemic sclerosis was diagnosed and progressed slowly over subsequent years. By 1983 she had developed acro-osteolysis, flexion contractures of the fingers of the left hand, and fibrosing alveolitis. In 1984 she presented with abdominal pain and diarrhoea.

Investigations were as follows: haemoglobin $12 \cdot 0$

Accepted for publication 29 April 1986

Correspondence Dr C Sonnex, Department of Rheumatology, Whittington Hospital, Highgate Hill, London N19.

*Present address: Department of Genito-Urinary Medicine, Westminster Hospital, Dean Ryle Street, London SW1. g/dl $(120 \mathrm{~g} / \mathrm{l}) ;$ mean corpuscular volume $83 \mathrm{fl}$; erythrocyte sedimentation rate $35 \mathrm{~mm} / 1 \mathrm{st} h$ (Westergren); serum vitamin $B_{12} 230 \mathrm{ng} / 1$ (normal range 160-960 ng/l); red blood cell folate $180 \mathrm{pg} / \mathrm{l}$ (normal range $160-640 \mathrm{pg} / \mathrm{l}$ ); stool culture negative; urinary indicans normal; three day faecal fat excretion normal. A small bowel enema showed rapid transit of contrast without evidence of diverticula. Fibre optic sigmoidoscopy to $40 \mathrm{~cm}$ was normal. During the course of investigation she complained of fainting episodes. Marked postural hypotension was found, the blood pressure dropping from 125/70 $\mathrm{mmHg}$ lying to $95 /-\mathrm{mmHg}$ standing. We went on to test for autonomic neuropathy in greater detail as we considered this might possibly have contributed to the diarrhoea. Subsequent autonomic testing showed sympathetic and parasympathetic damage (see 'Results', Table 1, case 1).

Since autonomic dysfunction has not been previously described in systemic sclerosis we proceeded to test six other patients with scleroderma for evidence of sympathetic or parasympathetic damage.

\section{Subjects and methods}

Autonomic testing was performed on six patients with systemic sclerosis as defined by the American Rheumatism Association ${ }^{11}$ and on eight healthy control subjects attending our physiotherapy department with osteoarthrosis or soft tissue lesions. All were normotensive, none were in cardiac failure, anaemic, or receiving medications which influence cardiac rhythm. None had evidence of conditions previously described as relating to autonomic dysfunction. ${ }^{12}$ The methods used were those described by Ewing and Clarke ${ }^{13}$ and Smith. ${ }^{14}$ 


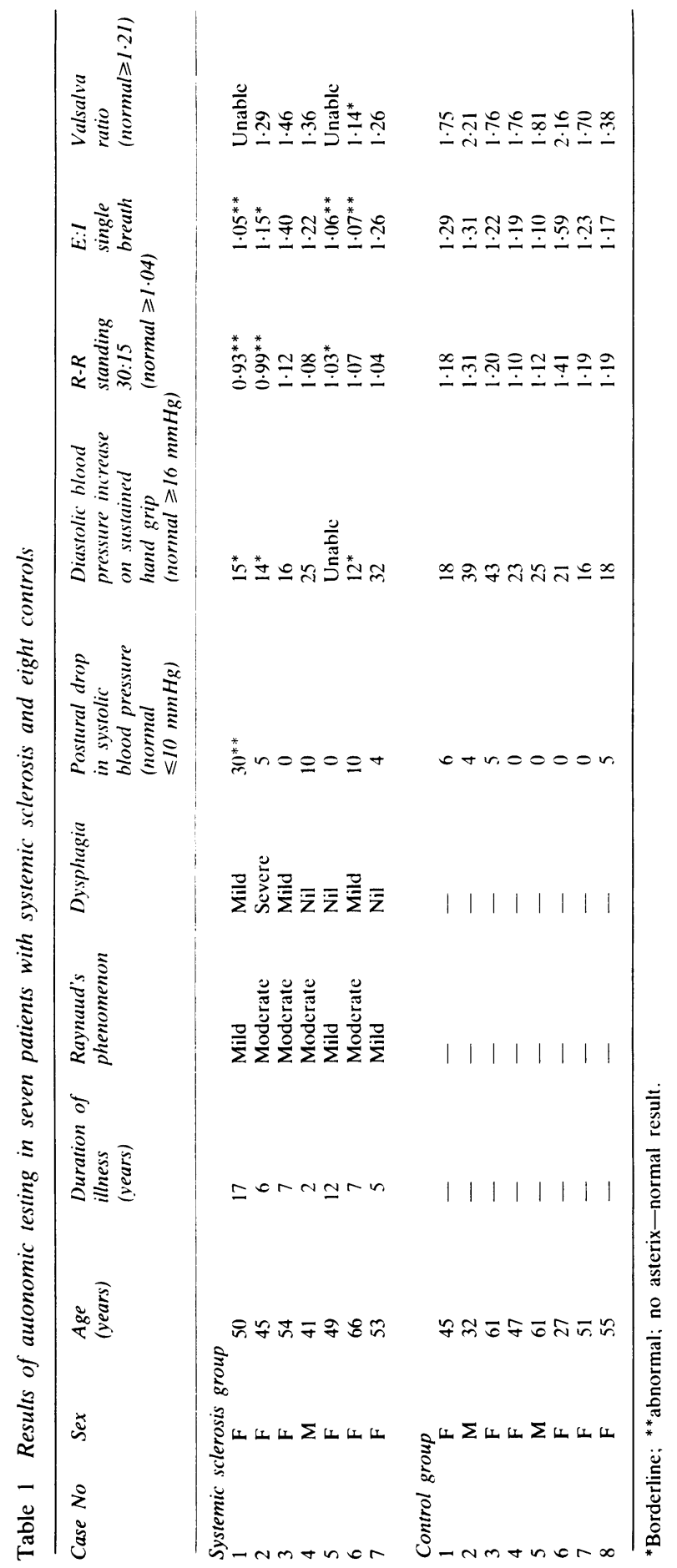


Cardiac parasympathetic integrity was initially assessed by measuring the heart rate response to standing by continuous electrocardiographic tracing. The shortest R-R interval at or around the 15 th beat after standing is compared with the longest $R-R$ interval at or around the 30 th beat. The $30: 15$ ratio is calculated, a result greater than or equal to 1.04 being regarded as normal. Ratios between 1.01 and 1.03 are borderline and below or equal to 1.00 abnormal. In addition we performed two further tests of parasympathetic function. The heart rate response to the Valsalva manoeuvre was measured for 15 seconds during the manoeuvre and for one minute after. The test was repeated three times and the mean of the three Valsalva ratios calculated (ratio of the longest R-R interval after the manoeuvre to the shortest $R-R$ interval during the manoeuvre). Values greater or equal to 1.21 are normal, 1.11 to 1.20 borderline, and below or equal to 1.10 abnormal. Measurement of the degree of sinus arrythmia resulting from a single forced respiratory cycle provided the final test for parasympathetic damage. The shortest $\mathrm{R}-\mathrm{R}$ interval during inspiration (I) and the longest during expiration (E) were measured and the E:I ratio calculated. The ratio was compared with the age related normal range. ${ }^{14}$

Sympathetic damage was initially assessed by measuring the postural fall in systolic blood pressure on standing from a lying position. The normal fall in systolic pressure is less or equal to $10 \mathrm{mmHg}$. An $11-29 \mathrm{mmHg}$ drop is borderline and greater than or equal to $30 \mathrm{mmHg}$ abnormal. Sympathetic damage was further assessed by measuring the rise in diastolic blood pressure on sustained hand grip. Maximum voluntary contraction was first determined with a hand grip dynamometer. Hand grip was then maintained at $30 \%$ of that maximum for as long as possible up to five minutes. Only one patient (case No 5) was unable to perform the test. The normal increase in diastolic blood pressure during this test is greater than or equal to $16 \mathrm{mmHg}$. An increase of $11-15 \mathrm{mmHg}$ is borderline and less than or equal to $10 \mathrm{mmHg}$ abnormal.

Evidence of peripheral neuropathy was assessed by measuring vibration threshold with a biothesiometer. The medial malleoli and great toes of both feet were tested and results compared with age related centile charts as devised by Bloom et al. ${ }^{15}$ In case 1 motor and sensory nerve conduction velocities were measured to confirm the result obtained by biothesiometer.

\section{Results}

The results of autonomic testing in seven patients with systemic sclerosis and eight controls are shown in Table 1 . Case 1 showed both sympathetic and parasympathetic damage. Of the six further patients with systemic sclerosis examined, three showed early parasympathetic dysfunction as defined by Ewing and Clarke. ${ }^{13}$

Vibration sensation thresholds were normal in both systemic sclerosis and control groups. In addition, case 1 had normal sensory and motor nerve conduction velocities.

Our results were compared with previously recorded normal ranges. ${ }^{13}{ }^{14}$ In addition we tested eight control patients ourselves, to ensure that our methodology was correct. All results of our control patients fell within the normal range.

\section{Discussion}

Autonomic neuropathy has not previously been reported in systemic sclerosis. It is not clear why such patients should develop autonomic dysfunction. Possibly it is caused by compression of nerve fibres by collagen as postulated in the aetiology of peripheral neuropathy in this condition. ${ }^{6}$ Damage to the vasa nervorum may also have a role

Diarrhoea is well recognised in systemic sclerosis. This may be due to a combination of vascular obstruction, altered motility, impairment of intestinal lymphatics, and bacterial overgrowth ${ }^{16}$ though in some cases it remains unexplained. We found no evidence of bacterial overgrowth, hypomotility, or malabsorption in our case. Autonomic neuropathy is thought to cause diarrhoea in patients with diabetes mellitus, and autonomic neuropathy may have contributed to or caused diarrhoea in our patient.

Oesophageal dysfunction develops in approximately $90 \%$ of patients with systemic sclerosis and may be one of the earliest manifestations. ${ }^{17}$ This is thought to be secondary to smooth muscle involvement, though autonomic neuropathy has not been previously assessed. In our small group of patients there appeared to be no correlation between the degree of dysphagia and autonomic dysfunction.

Raynaud's phenomenon occurs in up to $90 \%$ of patients with systemic sclerosis and may predate skin manifestations of the disease. Excess sympathetic activity was initially considered to be the cause by Raynaud in 1862, but this has not been substantiated. ${ }^{18}$ Indeed in our patients there was no correlation between the severity of Raynaud's phenomenon and autonomic dysfunction.

Autonomic neuropathy in patients with rheumatoid arthritis is usually associated with peripheral neuropathy. ${ }^{12}$ Our study group had normal vibration thresholds as assessed by the biothesiometer, 
which suggests normal sensory peripheral nerve function.

We thank Dr M L Snaith and Dr D A Isenberg, University College Hospital, London and Dr S Corcoran, Whittington Hospital, London for their assistance.

\section{References}

1 Edmonds M E, Jones T C, Saunders W A, Sturrock R D. Autonomic neuropathy in rheumatoid arthritis. Br Med J 1979; ii: $173-5$.

2 Leden I, Eriksson A, Lilja B, Sturfelt G, Sundkvist G. Autonomic nerve function in rheumatoid arthritis of varying severity. Scand J Rheumatol 1983; 12: 166-70.

3 Hoyle C, Ewing D, Parker A C. Acute autonomic neuropathy in association with systemic lupus erythematosus. Ann Rheum Dis 1985; 44: 420-4.

4 Lally $\mathrm{E} \mathrm{V}$, Jimenez S A. Impotence in progressive systemic sclerosis. Ann Intern Med 1981; 95: 150-3.

5 Kibler R F, Rose F C. Peripheral neuropathy in the collagen diseases. A case of scleroderma neuropathy. $\mathrm{Br} \mathrm{Med} \mathrm{J} \mathrm{1960;} \mathrm{i:}$ 1781-4.

6 Di Trapani G, Pocchiari M, Masullo C, Albanese A, Tulli A. Peripheral neuropathy in the course of progressive systemic sclerosis: light and ultrastructural study. Ital J Neurol Sci 1982; 3: 341-8.

7 Beighton P, Gumpel J M, Cornes N G. Prodromal trigeminal sensory neuropathy in progressive systemic sclerosis. Ann Rheum Dis 1968; 27: 367-96.
8 Tait B, Ashworth B. Trigeminal neuropathy in connective tissue disease. Ann Rheum Dis 1970, 29: 399.

9 Kabad U M, Sinkoff M W. Case report: Trigeminal neuralgia in progressive systemic sclerosis. Postgrad Med 1977; 61: 176-7.

10 Bjerregaard B, Højgarrd K. Neurological symptoms in scleroderma. Arch Dermatol 1976; 112: 1030-1.

11 Subcommittee for scleroderma criteria of the American Rheumatism Association diagnostic and therapeutic criteria committee. Preliminary criteria for the classification of systemic sclerosis. Arthritis Rheum 1980; 23: 581-90.

12 Henrich W L. Autonomic insufficiency. Arch Intern Med 1982; 142: $339-44$

13 Ewing D J, Clarke B F. Diagnosis and management of diabetic autonomic neuropathy. $\mathrm{Br} \mathrm{Med} J$ 1982; 285: 916-8.

14 Smith S A. Reduced sinus arrythmia in diabetic autonomic neuropathy; diagnostic value of age-related normal range. $\mathrm{Br}$ Med J 1982; 285: 1599-601.

15 Bloom S, Till S, Sönksen P, Smith S. Use of a biothesiometer to measure individual vibration thresholds and their variation in 519 non-diabetic subjects. $\mathrm{Br}$ Med $J$ 1984; 288: 1793-5.

16 Fisher R S, Myers A R. Systemic disease and the gut. In: Bouchier I A, Allan R N, Hodgson H J, Keighley M R, eds. Textbook of gastroenterology. London: Bàlliere Tindall, 1984: 642-9.

17 Poirer T J, Rankin G B. Gastrointestinal manifestations of progressive systemic sclerosis based on review of 364 cases. Am J Gastroenterol 1972; 58: 30-44.

18 Anonymous. Pathophysiology of Raynaud's phenomenon [Editorial]. Br Med J 1980; 285: 1027-8. 